\title{
Efeitos da alfabetização aplicada no ensino remoto durante a pandemia de covid-19: uma revisão literária
}

\author{
Effects of applied literacy in remote education during the covid-19 pandemic: a literary \\ review
}
Efectos de la alfabetización aplicada en la educación remota durante la pandemia del covid-19: una revisión literaria

Leila Maria Rainha Lemos ${ }^{1 *}$, Agna Lucia da Silva Sarlo.

\begin{abstract}
RESUMO
Objetivo: Apresentar os efeitos da alfabetização aplicada no ensino remoto durante a pandemia de Covid19, desde os diagnósticos referentes a saúde do aluno até as questões referentes as novas técnicas de aprendizado. Revisão Bibliográfica: Devido ao isolamento social decorrente da pandemia do novo Coronavírus, o ensino remoto $(\mathrm{EaD})$ se tornou uma alternativa para que os alunos não perdessem um ano de estudo. As grades foram mantidas e aplicadas através de videoaulas e atividades disponibilizadas por bases eletrônicas. Contudo nem todos os alunos conseguiram acompanhar o novo ritmo e as novas técnicas, além dos muitos que não tiveram acesso inicial a computadores ou aparelhos eletrônicos. Os efeitos dos novos métodos aplicados podem se dar desde a saúde mental dos alunos, passando pela saúde alimentar e chegando nas condições do aprendizado, que muito se perdeu e pouco se avaliou de fato sobre as formas de aderir o novo método. Considerações finais: $O$ ensino remoto, utilizado como alternativa para manter o funcionamento das aulas durante a pandemia, causou estranheza nos alunos e suas consequências.
\end{abstract}

Palavras-chave: Infecções por coronavírus, Pandemias, Aprendizagem.

\begin{abstract}
Objective: To present the effects of applied literacy in remote education during the Covid-19 pandemic, from diagnoses regarding student health to questions regarding new learning techniques. Bibliographic Review: Due to the social isolation resulting from the new Coronavirus pandemic, remote education (DE) has become an alternative for students not to miss a year of study. The grids were maintained and applied through video classes and activities provided by electronic bases. However, not all students were able to keep up with the new pace and new techniques, in addition to the many who did not have initial access to computers or electronic devices. The effects of the new methods applied can occur from the mental health of the students, when in the conditions of learning, that much has been lost and little has actually been evaluated on the conditions of adhering to the new method. Final considerations: Remote education, used as an alternative to maintain the functioning of classes during the pandemic, caused strangeness in students and its consequences.
\end{abstract}

Key words: Coronavirus infections, Pandemics, Learning.

\section{RESUMEN}

Objetivo: Presentar los efectos de la alfabetización aplicada en la educación remota durante la pandemia Covid-19, desde diagnósticos sobre la salud de los estudiantes hasta preguntas sobre nuevas técnicas de aprendizaje. Revisión bibliográfica: Debido al aislamiento social resultante de la nueva pandemia de Coronavirus, la educación remota (DE) se ha convertido en una alternativa para que los estudiantes no se pierdan un año de estudio. Las cuadrículas se mantuvieron y aplicaron a través de clases de video y actividades proporcionadas por bases electrónicas. Sin embargo, no todos los estudiantes pudieron mantenerse al día con el nuevo ritmo y las nuevas técnicas, además de los muchos que no tuvieron acceso inicial a computadoras o dispositivos electrónicos. Los efectos de los nuevos métodos aplicados pueden

\footnotetext{
${ }^{1}$ Faculdade Vale do Cricaré (FVC), São Mateus - ES. *E-mail: leilamroge@yahoo.com.br
} 
ocurrir desde la salud mental de los estudiantes, cuando en las condiciones de aprendizaje, se ha perdido mucho y se ha evaluado realmente poco sobre las condiciones de adhesión al nuevo método. Consideraciones finales: La educación a distancia, utilizada como alternativa para mantener el funcionamiento de las clases durante la pandemia, provocó extrañeza en los estudiantes y sus consecuencias.

Palabras clave: Infecciones por coronavirus, Pandemias, Aprendizaje.

\section{INTRODUÇÃO}

A Organização Mundial da Saúde (OMS) confirmou a pandemia de coronavírus COVID19 (doença coronavírus 2019) em 11 de março de 2020. Uma importante questão epidemiológica envolve o patógeno altamente infeccioso do SARS-CoV-2, cuja velocidade de transmissão pode variar de 1,6 a 4,1. A alta infectividade do SARS-CoV-2 e a falta de uma vacina contra esse vírus aumentaram exponencialmente 0 número de casos. No Brasil, governos estaduais e municipais têm tomado algumas medidas, como o fechamento de escolas e negócios não essenciais. Os trabalhadores são orientados a realizar atividades em casa. Algumas cidades e estados restringiram suas divisas. O poder público, em algumas localidades, já ordenou o bloqueio total e multou os locais e pessoas que não cumpriram a regulamentação (MALTA DC, et al., 2020).

Os coronavírus são uma grande família de vírus comumente encontrados em muitos tipos diferentes de animais, incluindo camelos, vacas, gatos e morcegos. Poucos coronavírus que infectam animais podem infectar humanos, como MERS-CoV e SARS-CoV. Recentemente, em dezembro de 2019, um novo coronavírus (SARS-CoV-2) foi espalhado, o qual foi descoberto em Wuhan, China e causou o COVID-19, e então o espalhou de pessoa para pessoa. COVID-19 é uma doença causada por um coronavírus, denominado SARS-CoV-2, e sua gama clínica varia de infecções assintomáticas a doenças graves. De acordo com estatísticas da Organização Mundial de Saúde, a maioria (cerca de 80\%) dos pacientes com COVID-19 pode ser assintomática (raramente sintomática), e cerca de $20 \%$ dos casos detectados requerem hospitalização por dificuldades respiratórias. Cerca de $5 \%$ deles podem necessitar de suporte ventilatório (BRASIL, 2020).

De acordo com pesquisa realizada por Dias E e Pinto FCF (2020), em relação à educação, de acordo com a Organização das Nações Unidas para a Educação, a Ciência e a Cultura (UNESCO), sabemos que a crise provocada pela Covid-19 levou ao fechamento de escolas e salas de aula de universidades, afetando mais de 90 por cento dos alunos do mundo. Desse número, pergunta-se: qual o futuro da educação em um mundo abalado pelo novo coronavírus?

Quando as escolas forem reabertas e, em algumas partes do mundo tal evento já começou, a recessão econômica que se seguirá certamente aumentará as desigualdades e poderá reverter o progresso de alguns países no aumento do acesso à educação e na melhoria do aprendizado. Portanto, é imprescindível que os países reconheçam o problema - o que não aconteciam quando a COVID-19 começou a se espalhar pelo mundo - e criem políticas públicas voltadas especificamente para a educação (DIAS E e PINTO FCF, 2020).

No caso do distanciamento social, medida preventiva mais eficaz contra doenças, houve a necessidade de reavaliar o processo ensino-aprendizagem, pois o distanciamento social obrigou alunos de todo o mundo a adotarem as tecnologias de informação e comunicação (TIC) para dar continuidade à rotina de estudos. Consequentemente, as TIC e a Internet são cada vez mais utilizadas pelas instituições de ensino para compensar esta ausência nas salas de aula. No entanto, precisamos considerar se esse novo método de ensino e aprendizagem pode impactar o aprendizado dos alunos. Com o início da pandemia, as estratégias de ensino à distância são um meio importante de reduzir os efeitos do distanciamento social, no entanto, as evidências sugerem que muitas lacunas serão criadas sem a interação professor-aluno (GOMES VTS, et al., 2020).

Além do medo de contrair a infecção, o COVID-19 criou um sentimento de insegurança em todos os aspectos da vida, desde a perspectiva coletiva à individual, do funcionamento do dia-a-dia da sociedade às mudanças nas relações interpessoais. Quando se trata de saúde mental, deve-se dizer que as consequências de uma pandemia superam as mortes. Os sistemas de saúde dos países estão em colapso, os profissionais 
de saúde estão exaustos de muitas horas de trabalho e, além disso, o método mais eficaz de controle das doenças, que é a distância social, tem um impacto significativo na saúde mental da população (FARO A, et al., 2020).

Após problematizar o tema proposto, elenca-se como objetivo desta pesquisa apontar os efeitos do ensino remoto como agente de alfabetização durante a pandemia do novo Coronavirus. Efeitos esses que causam danos desde a saúde mental, passando pela saúde alimentar e os danos causados à capacidade de aprendizado dos alunos.

\section{REVISÃO BIBLIOGRÁFICA}

De acordo com a Organização das Nações Unidas para a Educação, Ciência e Cultura, 186 países ou regiões fecharam escolas, total ou parcialmente, no início de maio de 2020 para conter a propagação do Covid-19, atingindo cerca de $70 \%$ dos alunos. Este fechamento impactou o calendário escolar e seu impacto no aprendizado dos alunos é incerto. As diferenças no rigor da quarentena, na duração e nas estratégias adotadas pelas famílias e escolas são apenas alguns dos fatores que podem influenciar a trajetória desses alunos. Em meio à atual pandemia, a ciência, apoiada em evidências empíricas, começou a assumir uma importância irresistível. Portanto, compreender o impacto da Covid-19 na educação, com base no que dizem as evidências científicas, é importante para a sociedade (OLIVEIRA JBA, et al., 2020).

A necessidade de comunicação é inerente à biologia (especialmente à vida em sociedade). No entanto, apenas humanos podem manipular informações e registrar informações de forma consciente e intencional. Conscientize-se de que transmitir e receber informações é uma ação que pode ser vista através de pinturas rupestres desde a pré-história. Desde então, a comunicação escrita tornou-se uma condição do simbolismo social. Em todo o processo de desenvolvimento da humanidade, outras tecnologias relacionadas à comunicação também foram desenvolvidas e integradas à nossa cultura. A maior mudança trazida pela tecnologia não está focada na natureza substantiva ou virtual do mecanismo de transmissão e obtenção de informações, mas na forma como os humanos desviam e aproveitam a troca de informações (NASCIMENTO LMCT E GARCIA LAM, 2015).

O tempo da pandemia do coronavírus (COVID-19) trouxe um novo significado sem precedentes à educação. A perda de entes próximos, a evasão e o sofrimento causado pelo isolamento social levaram à ruptura da rotina e dos sistemas de ensino em sala de aula. A crise da saúde está trazendo a reforma do ensino para o ensino presencial, que é a mudança mais forte desde o surgimento das tecnologias de informação e comunicação contemporâneas. O surgimento da Internet intensificou o diálogo à distância e, a partir de meados da década de 1990, com o surgimento dos canais de pesquisa e diálogo (principalmente as redes sociais), as comunicações digitais se fortaleceram no Brasil (PASINI CGD, et al., 2020).

O cenário desencadeado pela pandemia fez com que professores e gestores tivessem que aplicar na prática as regras preconizadas pela Portaria ํㅜ 345/2020 do Ministério da Educação Nacional, que permite, de forma única, a substituição das aulas presenciais continuadas por atividades relacionadas com a utilização das tecnologias de informação e comunicação para a continuidade do semestre, e assim mesmo ano escolar. Consequentemente, há desafios para os professores aprenderem a usar as TIC na modalidade EAD para estimular os alunos a construir e buscar o conhecimento e, assim, garantir a conclusão do ano letivo (SILVA AF, et al., 2020).

A portaria dispõe que: Art. 1을 A Portaria MEC nํ3ㄱ, de 17 de março de 2020, passa a vigorar com as seguintes alterações:

"Art. 1ํ Fica autorizada, em caráter excepcional, a substituição das disciplinas presenciais, em andamento, por aulas que utilizem meios e tecnologias de informação e comunicação, por instituição de educação superior integrante do sistema federal de ensino, de que trata 0 art. $2^{\circ}$ do Decreto $n^{\circ}$ 9.235, de 15 de dezembro de 2017" (BRASIL, 2020). 
Nesta pandemia, devido à existência de desigualdades sociais, principalmente entre os grupos de baixa renda (desempregados e pessoas do setor informal), famílias e populações ficam mais vulneráveis à fragilidade social. As considerações sobre a saúde alimentar dos alunos também devem ser levadas em conta, já que muitos discentes ainda dependem da alimentação fornecida nas escolas para complementar o cardápio diário, o que foi dificultado com a pandemia do novo coronavírus, já que as escolas fecharam as portas e nem todas tiveram condições de disponibilizar alimentação para filhos de famílias menos providas de recursos (RIBEIRO-SILVA RC, et al., 2020).

A pandemia do coronavírus atingiu toda a estrutura social e quase não existem áreas da vida coletiva ou individual que não tenha tido impacto no campo da saúde mental. Em uma situação epidêmica, o número de pessoas afetadas pelo psicológico geralmente é maior do que o número afetado pela infecção. Estima-se que, se não forem atendidas adequadamente, um terço a metade da população pode ter consequências psicológicas. Porém, dadas as características inéditas de distância e isolamento social para milhões de pessoas ao mesmo tempo, o impacto da atual pandemia pode ser ainda maior, levando à hipótese de uma pandemia de medo e estresse (LIMA RC, 2020).

\section{Possíveis efeitos do ensino remoto na saúde dos alunos}

O acerto na construção de uma nova equipe de profissionais para lidar com as questões nacionais de saúde, bem como a necessidade de formar e qualificar esses trabalhadores nas áreas mais remotas do país, fazem da EAD uma estratégia para enfrentar desafios, aceitando novos conhecimentos e modelos de aprendizagem, consistência de novos modelos instrucionais com sugestões que ajudam a mudar a realidade. Acredita-se que a educação permanente é uma oportunidade para os trabalhadores da saúde estabelecerem uma postura crítica, autoavaliação, autoformação, autogestão e promoverem os ajustes necessários para a realização do trabalho nas disciplinas por meio da troca de saberes (CARBONERO FC, 2016).

Estudos com a população chinesa mostraram que esse confinamento em massa pode ter consequências psicológicas, e a China é o primeiro país a adotar a quarentena e o distanciamento social como medidas de proteção contra a disseminação do novo coronavírus. Os resultados mostraram que, em comparação com a população em geral, os índices de ansiedade, depressão, uso nocivo de álcool e distúrbios da saúde mental foram maiores. Geralmente, os pacientes com COVID-19 confirmado ou suspeito podem se preocupar com as consequências da infecção - que pode ser fatal, enquanto os pacientes na área de quarentena podem se sentir entediados, solitários e com raiva. E tais acontecimentos se passam na maioria das vezes com adultos, logo se imagina quais consequências podem atingir crianças e adolescentes devido ao isolamento (DUARTE $M Q$, et al., 2020).

Além de problemas de saúde, esta nova doença também reflete graves consequências sociais e agrava a pobreza e a fome. É cada vez mais claro que as consequências mais graves desta epidemia ocorrem em pessoas que já se encontram em situação de risco e vulneráveis antes do aparecimento do vírus no país, o que evidencia ainda mais a desigualdade social, étnica e de gênero. A população vive uma grave crise crônica causada por uma série de consequências de distúrbios sociais. Dentre os itens da agenda pública existentes para o alívio das consequências da fome, destaca-se o Programa Nacional de Alimentação Escolar (PNAE), onde a alimentação escolar brasileira não só prevê a erradicação da fome, mas também oferece educação alimentar e nutricional e satisfação. As necessidades nutricionais dos alunos nesse período promoveram o crescimento e desenvolvimento biológico psicossocial, a aprendizagem, o rendimento escolar e a formação de hábitos alimentares saudáveis (BICALHO D e LIMA TM, 2020).

As consequências de uma mudança repentina no ensino escolar podem ir muito além das barreiras aquisição de conhecimento. Não só as interações com os educadores estão em risco, mas também à saúde de quem vai absorver e quem transmite conhecimento. O cérebro humano nem sempre é familiar a mudanças a curto prazo, e ainda assim reage a essas mudanças, exemplos disso são mudanças no humor e comportamento na sociedade. É muito comum diferença de humor e no comportamento do aluno quando ele passa por uma mudança repentina em sua vida diária, é possível observar tais situações quando ocorre a separação de seus pais, quando muda o ambiente e até quando perde um ente querido (FALKENBERG MB, et al., 2014). 
A saúde mental foi colocada à prova extrema na pandemia de Covid-19. Inúmeras influências inesperadas já apareceram ou surgirão com o tempo. Uma mudança tão repentina não poderia funcionar de outra forma, visto na constante formação e complexidade do que se adapta ao cérebro humano de um adulto e produz uma série de efeitos, é compreensível que em crianças e adolescentes que ainda não tiveram o cérebro formado, esses efeitos sejam mais graves e complexos. A fim de ser capaz de construir um ambiente mais saudável que evite doenças mentais nos alunos e se torne um problema crescente no futuro, uma análise cuidadosa dos riscos que a sobrecarga de emoções traz é necessária, e como as novas técnicas podem ser introduzidas sem prejudicar o aluno (RAMOS LS, et al., 2020).

O contato com outras pessoas é essencial para desenvolver a comunicação interpessoal e compartilhar um senso de espaço social. Violar a política de convivência, principalmente para crianças e adolescentes que passaram a absorver o hábito da convivência, sem dúvida, levará ao comprometimento ao longo da vida. Para uma pessoa com saúde mental plena, isso é inimaginável, ela não precisa viver em um ambiente densamente povoado, para quem não consegue respeitar ou conhecer o espaço dos outros, também é difícil analisar a experiência de saúde. Os estudos sociais fornecem diagnósticos raros de pessoas que são incapazes ou não querem se adaptar. Esses estudos são vistos como oportunidades escassas de compreender a personalidade humana (KINKER FS, et al., 2018).

É compreensível que, pelo menos para desenvolver tratamentos formais ou métodos de prevenção seguros, novos métodos devem ser amadurecidos e novos estilos de vida devem ser desenvolvidos. No entanto, é uma prática mais saudável alocar as doses de acordo com as funções para que o novo método se torne um hábito menos prejudicial. É preciso aguardar a avaliação de profissionais que estudam o comportamento e o cérebro humano, pois, mesmo para eles, isso é novo e seu tempo de análise deve ser respeitado. Enquanto todos os requisitos científicos no campo da saúde mental ainda não estão maduros, é impossível explicar como avançar e se desenvolver com segurança em uma sociedade que mudará definitivamente seu comportamento (DE TROI M e QUINTILIO W, 2020).

\section{0 ensino remoto na alfabetização brasileira}

Novas tecnologias de informação e comunicação (TIC) estão causando mudanças comportamentais pessoas e educação. Essas tecnologias fazem parte do dia a dia dos alunos, escolas e universidades. Os alunos dessa geração de tecnologia são chamados de nativos digitais. Professores de diferentes áreas do conhecimento são incentivados a incluir atividades pedagógicas que incluem ativos tecnológicos como a Internet. Embora haja um enorme potencial a ser explorado no contexto da educação, professores e alunos precisam se sentir seguros sobre seu potencial essas tecnologias. Em termos de produtividade e criatividade, professores e alunos estão desempenhando cada vez mais papéis neste novo ambiente, portanto, suporte técnico e métodos de ensino precisam ser discutidos (SOUSA MJA, 2020).

A educação a distância (EaD) no Brasil foi criada e desenvolvida por meio de programas privados e decreto governamental, e sua trajetória de desenvolvimento evoluiu com a introdução e desenvolvimento de cada tecnologia no país. Portanto, a educação a distância atravessou a era dos correios, do rádio e da televisão, e hoje vive a era da Internet, e em cada período, de acordo com suas circunstâncias, um certo número de erros e acertos, contradições e contradições se acumularam. Inesperadamente, por vivermos em um país com escala continental e problemas estruturais no campo da educação, precisamos urgentemente de correção. Em cada era, a EaD aliou-se a sucessivos governos, e esses governos a utilizam como uma forma economicamente viável de expandir o acesso para superar potenciais lacunas educacionais em várias regiões do país (GOMES LF, 2013).

No Estado de São Paulo, a proposta inicial trazia a educação para ser ministrada de forma mais próxima do ensino e do entretenimento, ao invés de uma educação crítica e transformadora. Por meio de apresentações de videoaulas isoladas e interligadas, materiais didáticos impressos utilizados pelas unidades escolares foram apresentados de forma diferentes por professores. As diferenças socioeconômicas podem aumentar a lacuna entre a educação pública e privada porque os alunos podem ou não usar a mídia digital, independentemente de terem uma conexão de banda larga (FARIAS MZ e GIORDANO CC, 2020). 
Durante uma pandemia, são muitos os obstáculos para mobilizar as opiniões e posições do governo para minimizar essas questões e traçar novas perspectivas. A educação básica é entendida como direito público subjetivo e amparada pela Constituição Federal de 1988, que não é diferente. No Brasil, muitas redes de ensino optaram pelo método de ensino a distância, que é uma educação a distância improvisada (EaD), ansiosa por produzir materiais didáticos para que os alunos possam estudar em casa e permitir que os professores participem da gravação de cursos em vídeo e transmitidos ao vivo em várias plataformas virtuais. Tratar da garantia fundamental á educação, é dar ênfase à necessidade de se produzir métodos aplicáveis e sustentáveis de transmissão do ensino (EPUFABC, 2020). O texto constitucional dispõe que:

"Art. 205 A educação, direito de todos e dever do Estado e da família, será promovida e incentivadacom a colaboração da sociedade, visando ao pleno desenvolvimento da pessoa, seu preparo para oexercício da cidadania e sua qualificação para o trabalho.

Art. 2060 ensino será ministrado com base nos seguintes princípios:

I - igualdade de condições para o acesso e permanência na escola;ll - liberdade de aprender, ensinar, pesquisar e divulgar o pensamento, a arte e o saber;/II - pluralismo de idéias e de concepções pedagógicas, e coexistência de instituições públicas eprivadas de ensino;IV - gratuidade do ensino público em estabelecimentos oficiais; $V$ - valorização dos profissionais do ensino, garantido, na forma da lei, plano de carreira para omagistério público, com piso salarial profissional e ingresso exclusivamente por concurso públicode provas e títulos, assegurado regime jurídico único para todas as instituições mantidas pela União;VI - gestão democrática do ensino público, na forma da lei;VII - garantia de padrão de qualidade" (BRASIL, 1988).

O ensino remoto, por mais que possa parecer uma forma de garantir a educação que está prevista na Constituição de 1988, pode acabar se tornando um pesadelo para o futuro educacional brasileiro, já que não se sabe a reação do alunado e como a influência dessa nova forma de ensino vai resultar para os discentes. É importante destacar que não se pode desprezar dúvidas frequentes, como por exemplo, se as crianças e adolescentes estão prontos para lidar com isolamento social e carga de estudos diária sem uma orientação mais presente de um professor (RAMOS LS, et al., 2020).

A forma como os alunos se comporta no ambiente escolar é objeto de muitos estudos com objetivos claros. O objetivo aventado é obter o melhor conhecimento, reduzindo a fadiga, reduzindo custos e reduzindo estratégias desanimadoras. Chamar atenção é como decifrar um mistério, pois nenhum aluno possui semelhanças óbvias de personalidade, por isso é necessário desenvolver um método que inclua o maior número possível de indivíduos. O resultado de métodos imperfeitos é um aprendizado pobre e danos ao desenvolvimento escolar, o que pode causar uma série de problemas no desenvolvimento do intelecto e no curso do progresso acadêmico (SILVA GV, et al., 2019).

\section{CONSIDERAÇÕES FINAIS}

A saúde dos alunos pode estar comprometida com métodos pouco conhecidos e averiguados pelos cientistas da educação e da saúde. A alfabetização através de ensino remoto requer uma maior análise e um número mais amplo de pesquisas experimentais visando atender o coletivo no futuro. Não é prescindível que a prevalência das aulas, mesmo que à distância, tenham sua importância classificada acima das condições de saúde dos atores da vida educacional, podendo ser averiguado que sobrecarga de informações nas mentes dos discentes acarreta danos psicológicos.

\section{REFERÊNCIAS}

1. BICALHO D, LIMA TM. 2020. In: O PROGRAMA Nacional de Alimentação Escolar como garantia do direito à alimentação no período da pandemia do COVID-19. Disponível em: https://www.researchgate.net/publication/342571075_O_Programa_Nacional_de_Alimentacao_Escolar_como_garan tia_do_direito_a_alimentacao_no_periodo_da_pandemia_do_COVID-19. Acesso em: 1 de nov. 2020. 
2. BRASIL. 1988. Constituição da República Federativa do Brasil: promulgada em 5 de outubro de 1988. 4. ed. São Paulo: Saraiva, 1990.

3. BRASIL. 2020. In: O que é COVID-19. Brasília: Ministério da Saúde. Disponível em: https://coronavirus.saude.gov.br/sobre-a-doenca. Acesso em: 1 de nov. 2020.

4. BRASIL. 2020. In: PORTARIA № 345, DE 19 DE MARÇO DE 2020. Brasília: Ministério da Educação. Disponível em: https://www.in.gov.br/en/web/dou/-/portaria-n-345-de-19-de-marco-de-2020248881422? inheritRedirect=true\&redirect=\%2Fweb\%2Fguest\%2Fsearch\%3FqSearch\%3DPortaria\%2520345\%2520 de\%252019\%2520de\%2520mar\%25C3\%25A70\%2520de\%25202020. Acesso em: 2 de nov. 2020.

5. CARBONERO FC. Análise das publicações nacionais sobre educação a distância na área da saúde. Análise das publicações nacionais sobre educação a distância na área da saúde, 2016; 15(1): 51-59.

6. DE TROI M, QUINTILIO W. Coronavírus: lições anti-negacionistas e o futuro do planeta. SciELO em Perspectiva, 2020; ed on: 1-12.

7. DIAS E, PINTO FCF. A Educação e a Covid-19. Ensaio: Avaliação e Políticas Públicas em Educação, 2020; 28(108): 545-554.

8. DUARTE MQ, et al. COVID-19 e os impactos na saúde mental: uma amostra do Rio Grande do Sul, Brasil. Ciência \& Saúde Coletiva, 2020; 25(9): 3401-3411.

9. EPUFABC. 2020. In: ENSINO REMOTO na Educação Básica e COVID-19: um agravo ao Direito à Educação e outros impasses. São Paulo: Proec. Disponível em: http://proec.ufabc.edu.br/epufabc/ensino-remoto-na-educacao-basica/. Acesso em: 2 de nov. 2020.

10. FALKENBERG MB, et al. Educação em saúde e educação na saúde: conceitos e implicações para a saúde coletiva. Ciência \& Saúde Coletiva, 2014; 19(3): 847-852.

11. FARIAS MZ, GIORDANO CC. Educação em tempos de pandemia de COVID-19: Adaptação ao ensino remoto para crianças e adolescentes. Série Educar, 2020; 7(44): 60-71.

12. FARO A, et al. COVID-19 e saúde mental: a emergência do cuidado. Estudos de Psicologia (Campinas), 2020; 37(1): 1-11.

13. GOMES LF. EAD no Brasil: perspectivas e desafios. Avaliação: Revista da Avaliação da Educação Superior (Campinas). 18(1): 13-22.

14. GOMES VTS, et al. A Pandemia da Covid-19: Repercussões do Ensino Remoto na Formação Médica. Revista Brasileira de Educação Médica, 2020; 44(4): 1-10.

15. KINKER FS, et al. O desafio da formação permanente no fortalecimento das Redes de Atenção Psicossocial. Interface (comunicação, saúde e educação), 2018; 22(67): 1247-1256.

16. LIMA RC. Distanciamento e isolamento sociais pela Covid-19 no Brasil: impactos na saúde mental. Physis: Revista de Saúde Coletiva, 2020; 30(2): 1-10.

17. MALTA DC, et al. A pandemia da COVID-19 e as mudanças no estilo de vida dos brasileiros adultos: um estudo transversal, 2020. Epidemiol Serv Saúde, 2020; 11(3): 1-25.

18. NASCIMENTO LMCT, GARCIA LAM. Letramento em tempos de novas tecnologias de informação, comunicação e expressão. R. Bras.de Ensino de C\&T, 2015; 8(3): 222-235.

19. OLIVEIRA JBA, et al. A Covid-19 e a volta às aulas: ouvindo as evidências. Ensaio: Avaliação e Políticas Públicas em Educação, 2020; 28(108): 555-578.

20. PASINI CGD, et al. A educação híbrida em tempos de pandemia: algumas considerações. Observatório socioeconômico da covid-19, 2020: 1-9.

21. RAMOS LS, et al. A saúde mental do aluno prejudicada pelos métodos didáticos aplicados no isolamento social: um exame bibliográfico. Revista Eletrônica Acervo Saúde, 2020; 59(1): 1-8.

22. RIBEIRO-SILVA RC, et al. Implicações da pandemia COVID-19 para a segurança alimentar e nutricional no Brasil. Ciência \& Saúde Coletiva, 2020; 25(9): 3421-3430.

23. SILVA AF, et al. Saúde mental de docentes universitários em tempos de pandemia. Physis: Revista de Saúde Coletiva, 2020; 30(2): 1-4.

24. SILVA GV, et al. Promoção de saúde mental para adolescente em uma escola de ensino médio - Um relato de experiência. Revista do NUFEN, 2019; 11(2): 133-148.

25. SOUSA MJA. Percepções de Qualidade dos Alunos de Aulas Remotas de Pós-graduação: o Estudo em uma IES do Estado do Pará. EaD em Foco, 2020; 10(3): 1-13. 